\title{
Las vicisitudes de La Internacional Comunista*
}

\author{
Daniela Spenser
}

$\mathrm{P}$ OR INICIATIVA de Vladimir Ilich Lenin, la Tercera Internacional o Internacional Comunista se fundó en 1919 para que bajo el liderazgo de los bolcheviques promoviera la revolución mundial. ${ }^{1}$ Después de múltiples cambios de objetivos y formas de organización Josef Visarionovich Stalin la disolvió durante la Segunda Guerra Mundial. En la lucha por preservar la seguridad de la URSS el dirigente ruso necesitaba demostrar a sus aliados en el combate total contra el nazifascismo que el gobierno de la Unión Soviética se disociaba de una organización cuyo objetivo había sido derrocar el régimen burgués y el sistema capitalista. En la comunica-

DANIEL SPENSER: CIESAS.

* Este ensayo bibliográfico es un avance en el estudio de la Internacional Comunista en México basado en los archivos rusos. En colaboración con Rina Ortiz, la autora del ensayo está elaborando cuatro volúmenes de documentos que, bajo el título general La Internacional Comunista en México, profundizarán en algunos de los temas aquí señalados. Los documentos de la Internacional Comunista se encuentran en el Archivo de la historia sociopolítica del gobierno ruso en Moscú que la autora examinó extensamente en 1994.

${ }^{1}$ La Primera Internacional o la Asociación Internacional de los Trabajadores fue creada por Karl Marx en 1864 y disuelta en 1876 . La Segunda Internacional existió entre 1889 y 1914. La Tercera Internacional se conoce también como Komintern por la abreviación rusa de Komunisticheskii Internatsional. En ruso, su género es masculino, por lo que el sustantivo Komintern debe emplearse como masculino. Sin embargo, en la literatura sobre el tema se emplea también como la Comintern, por su asociación con la Internacional Comunista. Aquí emplearemos el género masculino y la letra inicial $\mathrm{K}$.

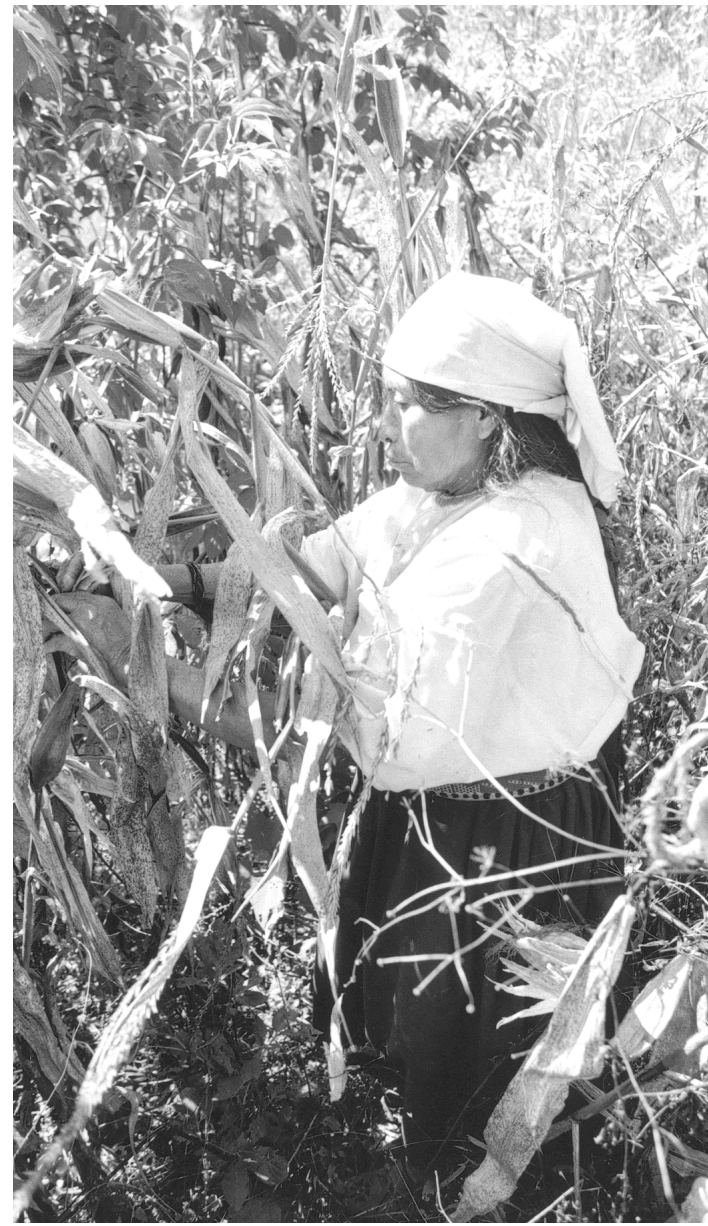

Espíritu Santo, mixe, Vittorio D’Onofri, 1995 


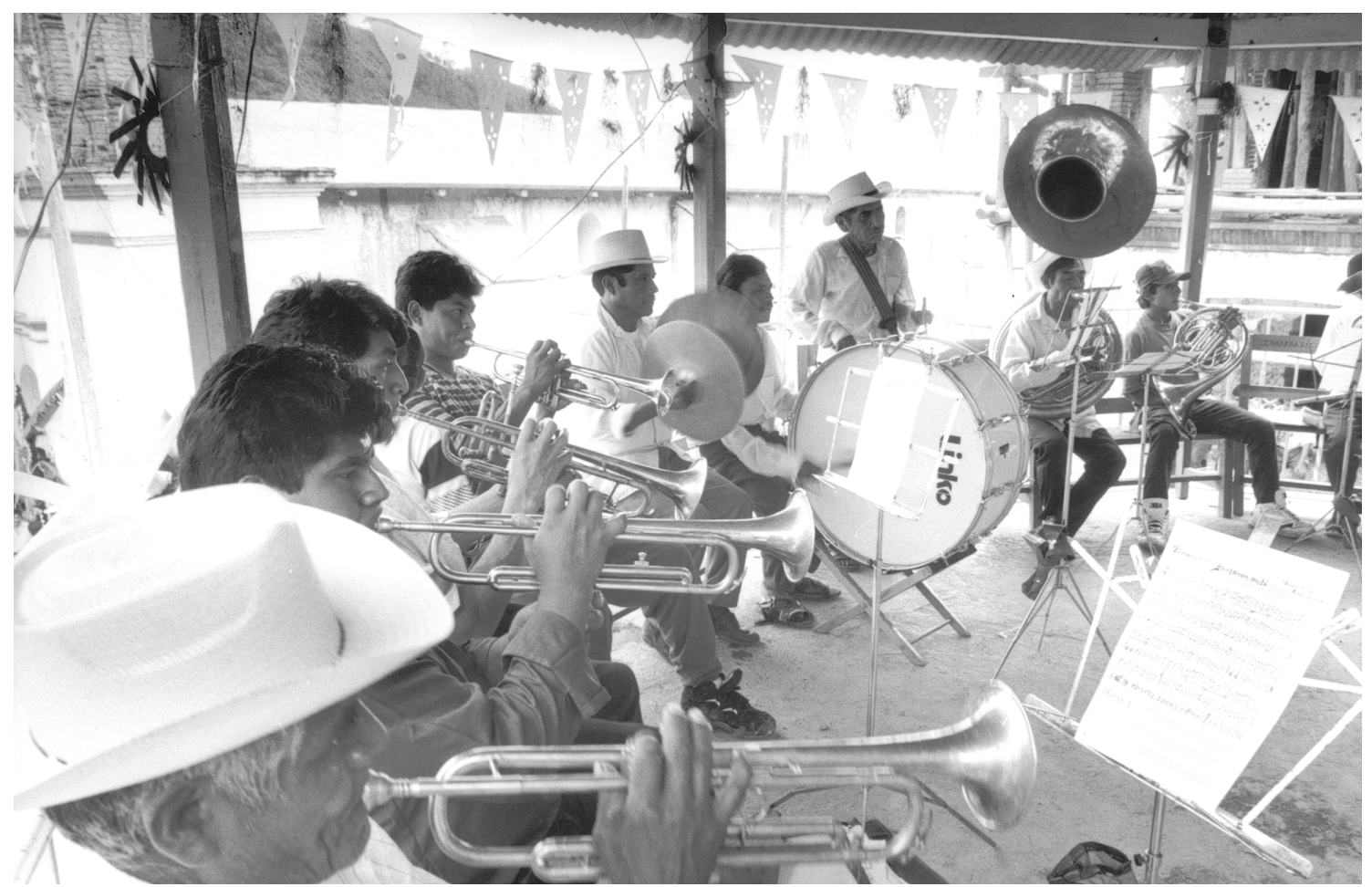

ción oficial a los partidos comunistas nacionales el vocero de Stalin en el Komintern, Georgi Dimitrov, alegó que la organización internacional fue disuelta para otorgarles a los partidos una autonomía y fortaleza mayores. ${ }^{2}$

Desde sus orígenes, el Komintern ha sido estudiado por amigos y enemigos, ha sido objeto de innumerables estudios académicos y sujeto al escrutinio de las agencias de inteligencia del mundo entero. Si bien los estudios sobre la Internacional Comunista nunca han dejado de producirse, a partir de los años ochenta se han multiplicado fuera y dentro de la Unión Soviética. Desde la apertura de los archivos soviéticos en los años noventa, la misma producción se ha enriquecido historiográfica y metodológicamente, aunque no han faltado publicaciones polémicas y controvertidas.

2 Paolo Spriano, Stalinism and the European Communists, Verso, Londres, Inglaterra, 1981, pp. 192-204; Alexander Dallin y F. I. Firsov (eds.), Dimitrov \& Stalin, 1934-1943. Letters from the Soviet archives, Yale University Press, New Haven, 2001, pp. 237-238.
A continuación presentaré algunos de los recientes debates y enfoques sobre la Internacional Comunista que han surgido a raíz de la apertura de los archivos. El acceso a los nuevos documentos estimuló una crítica de la historiografía creada durante el periodo de la guerra fría así como de la literatura revisionista que surgió en reacción a la literatura anticomunista. ${ }^{3}$ Además, señalaré algunos de los temas que han sido repensados gracias a la discusión suscitada a la luz de los nuevos documentos. En la última parte del artículo me centraré en la revisión historiográfica y en el debate sobre la trayectoria del Komintern como el partido de la revolución mundial primero, que después de que la revolución había sido "traicionada", ${ }^{4}$ pospuesta o abandonada, se transformó en uno de los instrumentos de la política exterior del estado soviético.

\footnotetext{
${ }^{3}$ Michael Brown, Randy Martin, Frank Rosengarten, George Snedeker (eds.), "New studies in the politics and culture of U.S. communism", en Monthly Review Press, Nueva York, 1993.
} 


\section{EL KOMINTERNY LA APERTURA IDEOLÓGICA EN LA UNIÓN SOVIÉTICA}

La apertura ideológica y la transparencia de información (glasnost) — promovidas desde 1985 por el secretario general del Partido Comunista Mijail Gorbachov en la URSS - dieron luz a nuevos estudios sobre el Komintern; sin ellas hubieran seguido guardados bajo llave o nunca escritos. Cuando solamente algunos historiadores, como el director del Instituto del marxismo-leninismo del Comité Central del Partido Comunista de la URSS, Fridrij Firsov y sus colaboradores, podían consultar los archivos del Komintern, existía todavía la esperanza de que la Internacional, como la organización mundial de los trabajadores, podía ser reivindicada. Era cierto que los archivos revelaban las atrocidades que Stalin había cometido en contra de los colaboradores cercanos de Lenin desde mediados de los años veinte, en contra de las direcciones enteras de los partidos comunistas nacionales, como fue el caso del partido polaco en los años treinta, las imposiciones de tácticas que a la postre demostraron ser desastrosas como la lucha contra los socialdemócratas a principios de los años treinta en Alemania cuando el nacionalsocialismo demostraba su lado tenebroso. Pero los estudiosos como Firsov consideraron estos hechos como errores que no deslegitimaban el movimiento comunista y su organización, el Komintern. Por lo menos en 1989, Firsov todavía creía que el estudio "de la experiencia histórica y la recuperación de la verdad histórica ayudarían a desarraigar completamente el estalinismo y a restaurar y desarrollar mejor el concepto de Lenin del movimiento comunista. Sin duda, la apertura de los archivos del Komintern contribuirá a ese objetivo". ${ }^{5}$ De acuerdo con las ideas que subyacían al proyecto de perestroika (reconstrucción) antes de que la URSS desapareciera y el Partido Comunista fuera temporalmente ilegalizado en 1991, los intelectuales en la Unión Soviética, como Firsov, creían en la posibilidad de democratizar el sistema

\footnotetext{
${ }^{4}$ La alusión es al trabajo de León Trotsky, La revolución traicionada, publicado en 1937 .

${ }^{5}$ Fridrij Firsov, "What the Komintern's archives will reveal", en World Marxist Review, vol. 32, enero de 1989, p. 57.
}

soviético. Fue esta esperanza la que influyó sobre el retraso de la investigación crítica y a fondo de la historia del Komintern. Sin embargo, durante los años de la perestroi$k a$ tuvo lugar una interacción entre el discurso académico y el público que permitió sacudir algunas de las tanto tiempo acariciadas verdades sin que el régimen abandonara las interpretaciones centrales del pasado soviético como su adhesión a las enseñanzas de Lenin y el leninismo. ${ }^{6}$

El ambiente intelectual en la URSS cambió cuando el sistema soviético se desmoronó y hacía falta una explicación de su abigarrado pasado y su progresivo debilitamiento. Inicialmente al menos surgió la tendencia de buscar a los culpables del descalabro político del coloso del este, empezando por el enjuiciamiento del Partido Comunista de la URSS. En 1991 Boris Yeltsin, el nuevo presidente, mandó abrir los archivos del Comité Central del PCUs para que los archivistas sacaran a la luz pública los documentos que pusieran en evidencia que el partido era una organización criminal y debía ser puesta fuera de la ley. Aunque este arranque de apertura de los archivos tuvo como consecuencia la aparición de documentos jamás vistos, no se trataba de una investigación sistemática. Una vez reemplazado el inicial estado de ánimo por la urgencia de la institucionalización del nuevo régimen postsoviético, los archivos del Comité Central del PCUS volvieron a cerrarse. ${ }^{7}$

A diferencia de la interpretación política de la historia de la URSS, la nueva rendición de la historia del Komintern recibió un empuje sin precedentes en 1991, cuando los archivos que contenían los distintos fondos relativos

\footnotetext{
${ }^{6}$ Andreas Langenhol, "History between politics and public: historiography, collective memory, and the archival revolution in Russia", en Kritika, núm. 3, vol. 1, verano de 2000, pp. 560-5623.

7 Patricia Kennedy Grimsted, Archives of Russia five years after: "purveyors of sensations" or "shadows cast to the past"? International Institute of Social History, Amsterdam, 1997, p. 131. Gracias a esta primera, aunque errática apertura de uno de los archivos más resguardados, contamos con un importante acervo que revela, entre otros datos, la periodicidad y los montos de financiamientos otorgados a los partidos comunistas por el PCUS. Véase Rossiskii gosudarstvennyi arjiv noveishei istorii, fond 89 . Este fond fue microfilmado por la compañía Chadwyck-Heeley de Gran Bretaña y varias copias están depositadas en las bibliotecas de Estados Unidos. Agradezco a Leonora Soroka, archivista de la institución Hoover en la Universidad de Stanford, por haberme proporcionado las fotocopias del fond relativas a los partidos comunistas de América Latina y la información sobre su peculiar adquisición.
} 
a las actividades del Komintern se abrieron al público en general. A partir de entonces, los historiadores podían examinar las estructuras de los órganos públicos y algunos secretos de la Tercera Internacional y de los fondos de los partidos comunistas nacionales. Acervos como los archivos del KGB y los personales de los altos funcionarios del Estado y del partido soviético permanecieron, salvo contadas excepciones, cerrados. No obstante, y después de haber superado la tradicional desconfianza hacia el poder, los historiadores soviéticos eran los primeros en empezar a develar la compleja historia que en gran parte había sido oculta. En búsqueda de la verdad histórica y sin preparación metodológica para digerir la avalancha de tanta información, algunos historiadores y periodistas sucumbieron a confiar ingenuamente en los hechos históricos como la fuente de la verdad sin someter los documentos a una interpretación crítica. ${ }^{8}$

\section{LOS NUEVOS ENFOQUES}

Según la línea oficial soviética hasta antes de la época de glasnost y de la apertura de los archivos, el Komintern era una organización que había rendido grandes servicios al establecimiento y la consolidación de los partidos comunistas, a la convocación de las fuerzas revolucionarias del mundo, a la movilización para la lucha contra el fascismo, la guerra y en favor de la paz, de la independencia y

\footnotetext{
${ }^{8}$ Kevin McDermott, "Rethinking the Comintern: Soviet historiography, 1987-1991", en Labour History Review, vol. 57, parte 3, invierno de 1992, pp. 37-58. Sobre el acceso a los archivos de KGB, llamado el Servicio Ruso de Inteligencia Exterior a partir de 1991, véase Amy Knight, "The selling of the KGB", en The Wilson Quarterly, invierno de 2000, pp. 16-23. Knight examina los estudios supuestamente basados en los archivos del KGB, y explica sus limitaciones porque se basan en documentos entregados a los historiadores, en lugar de que los historiadores tengan la libertad de seleccionarlos por su cuenta Una excepción fue Vitali Chentalinski, De los archivos literarios del KGB, Barcelona, Anaya \& Mario Muchnik, 1994. Sobre los archivos, véase además Diane P. Koenker y Ronald B. Bachman (eds.), Revelations from the Russian Archives. Documents in English Translation, Library of Congress, Washington, 1997, p. XVII y XX. La falta de acceso al acervo de Stalin ha sido quizás la que más ha preocupado a los historiadores y periodistas rusos, quienes veían que "el que controla el pasado, controla el futuro". Véase Kennedy Grimsted, Archives of Russia five years later, p. 48; Langenohl, "History between politics and public", pp. 561, 567-568.
}

del socialismo. Presentaba al Komintern como el modelo de una organización que servía al pueblo trabajador y hacía avanzar las ideas del marxismo-leninismo. Esta versión destacaba las virtudes de la multiclasista alianza antifascista del frente popular de los años 1934-1939, mientras que apenas mencionaba el papel primordial de Stalin en la gradual pérdida de la vitalidad y la autonomía del Komintern frente a los aparatos del partido y del estado soviéticos. Dejaba del lado la influencia de Stalin en la conversión del Komintern en un brazo de la política interna y exterior de la URSS. Las purgas de los dirigentes bolcheviques promovidas por Stalin en los aparatos del Komintern y en las direcciones de los partidos comunistas durante los años veinte y treinta no merecían sino una mención de paso. El pacto de no agresión entre Stalin y Hitler, firmado en 1939, no figuraba como un hecho de importancia. Es cierto que la versión oficial de la historia del Komintern era crítica de las tácticas sectarias de finales de los años veinte conocidas como "clase contra clase" y "el social-fascismo", tácticas que habían separado a los comunistas de los socialdemócratas y debilitado su lucha común contra el fascismo. Sin embargo, después de haber hecho el balance, los historiadores soviéticos presentaban el legado histórico del Komintern como positivo en áreas como el internacionalismo proletario, la lucha revolucionaria, la unidad obrera, la lucha por la liberación nacional, por la democracia y el socialismo, todo ello de acuerdo con los principios revolucionarios marxista-leninistas. ${ }^{9}$

A medida que cambiaba el ambiente político e ideológico de la URSS en los años ochenta, los historiadores soviéticos no sólo incorporaban nuevos temas al estudio sobre el comunismo internacional, sino que modificaban el énfasis en sus estudios respecto a los historiadores de la época anterior. La libertad de expresión y la pérdida del temor a la persecución abrieron la posibilidad también para que los autores no académicos publicaran libros que recogían las experiencias y los recuerdos de los protagonistas de la historia y de las víctimas del régimen soviético. De hecho, la memoria colectiva se convirtió en una

\footnotetext{
${ }^{9}$ McDermott, "Rethinking the Comintern", p. 37.
} 
fuerza poderosa que contribuyó al derrumbe del régimen soviético, pues el recuerdo sistematizado del pasado fortaleció a la oposición política. Los textos que surgieron de este movimiento de derechos humanos, llamado $\mathrm{Me}$ morial, conservan un innegable interés historiográfico pues reflejan cómo los grandes procesos en contra de las oposiciones y las políticas del estado se vivían en la cotidianidad de los hombres y las mujeres, las familias y los grupos sociales que se sustraían al poder del estado. ${ }^{10}$

Uno de los personajes de la Revolución bolchevique que en la Unión Soviética estaba fuera de la discusión crítica hasta entonces era Vladimir Ilich Lenin. De repente, Lenin fue incluido como tema de estudio y de polémica. Inicialmente, los historiadores se limitaron a deslindar la fase leninista del Komintern de la estalinista lo cual los llevó a concluir que Lenin jugó un papel constructivo en los primeros años de la existencia del Komintern, mientras que al asumir Stalin el liderazgo del partido en los años veinte, distorsionó sus enseñanzas e ideas políticas. En estos estudios Lenin fue descrito como sensible a las condiciones y tradiciones nacionales, y el Komintern de su creación fue caracterizado como una organización en la que la toma de las decisiones era colectiva y flexible en el espíritu del centralismo democrático. ${ }^{11}$

Sin embargo, al avanzar el estudio de los documentos, sobre todo de los aparatos de la dirección del estado, del partido y del Komintern, los historiadores pusieron en duda el espíritu democrático de la Internacional aun bajo el liderazgo de Lenin. Citando una carta de Clara Zetkin, la edecán del comunismo alemán, acerca de la actitud altiva e intervencionista del Comité Ejecutivo del Komintern hacia los partidos extranjeros, el mismo Firsov llegó

\footnotetext{
${ }^{10}$ Véase Edvard Radzinsky, Stalin, Doubleday, Nueva York, 1996; Pavel y Anatoli Sudoplatov, Special Tasks. The Memoirs of an Unwanted Witness — a Soviet Spymaster, Little, Brown, Nueva York, 1994; Langenohl, "History between politics and public", pp. 559-560; Veronique Garros, Natalia Korenevskaia y Thomas Lahusen (eds.), Intimacy and terror: Soviet diaries of the 1930s, The New Press, Nueva York, 1995. Aunque no se puede generalizar, no hay que desdeñar el interés monetario de los autores y de las casas editoriales para que estos libros se escribieran, pues su valor comercial no ha sido nada desdeñable.

${ }^{11}$ Fridrij Firsov, Kirill Shirinia y Valentin Sirotkin, 'The Komintern", en Soviet Life, núm. 3, marzo de 1989, pp. 19-24; Dmitri Volkogonov, Lenin, Novosti, Moscú, 1994.
}

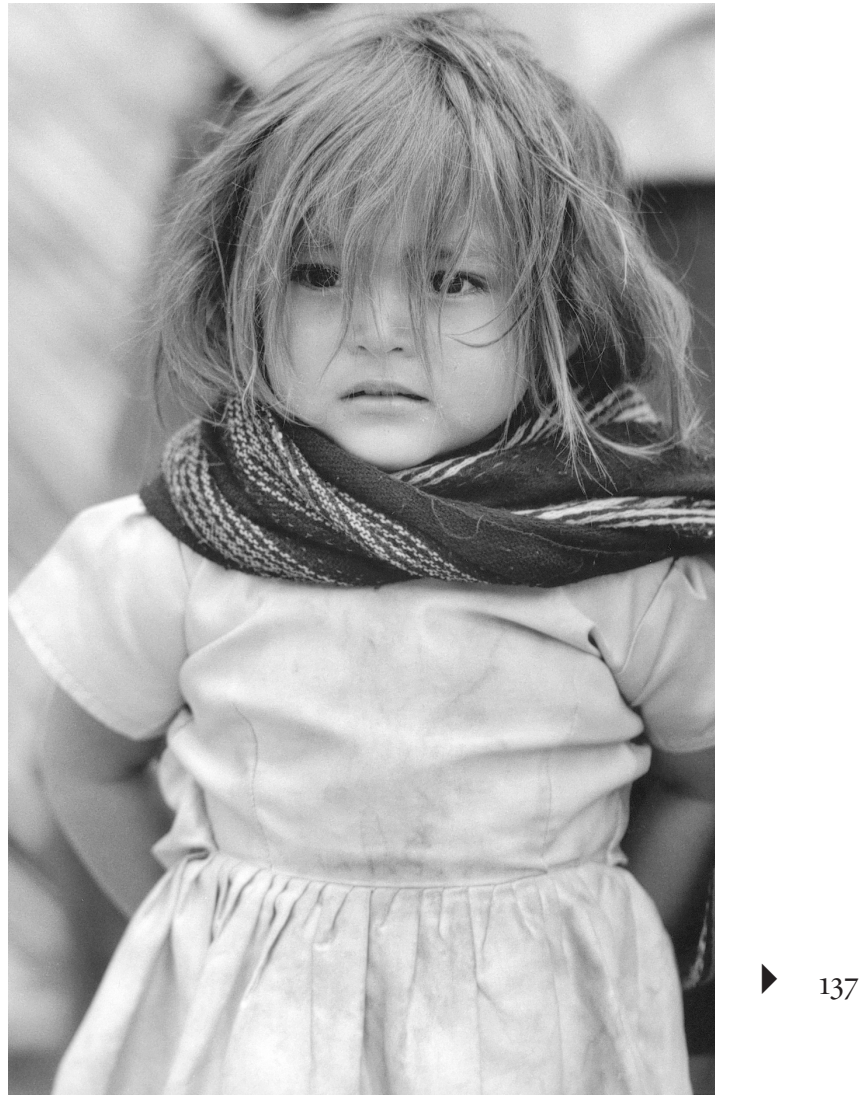

San Juan Teitipac, zapoteca del Valle, Vittorio D’Onofri, 1995

a cuestionar el funcionamiento democrático del Komintern aun en su primera fase. El estudioso ruso argumentó que de esta actitud a las directivas de Stalin había sólo un paso. Sin mencionar el nombre de Lenin, los historiadores como Firsov admitieron que desde el principio el Komintern estaba centralizado e interfería en la vida interna de los partidos. A su vez, los periodistas que basaban sus artículos en los documentos de los archivos, como por ejemplo los decretos tempranos del gobierno soviético y los escritos del propio Lenin como los llamados al uso de la coerción y terror contra los campesinos ricos considerados "enemigos del pueblo", exhortaban a los lectores a romper con los esquemas ortodoxos de pensar. ${ }^{12}$

12 Koenker y Bachman, Revelations from the Russian archives, p. XVIII. 


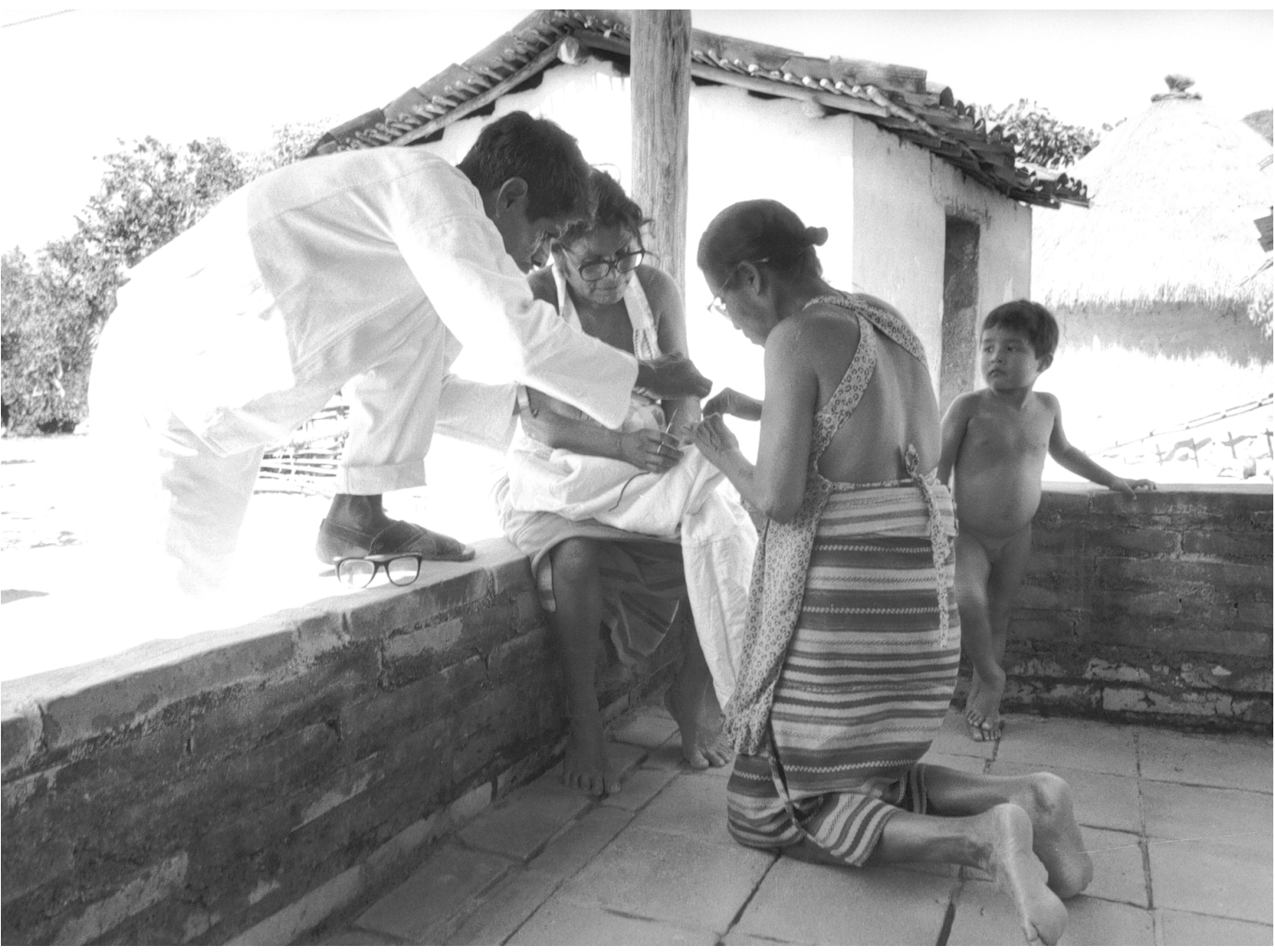

Santa María Jicaltepec, mixteca de la Costa, Vittorio D’Onofri, 1995

La táctica de frente unido que Lenin adoptó en 1921 ha provocado uno de los debates más polémicos. Tradicionalmente los historiadores rusos interpretaban su adopción como el medio para forjar la unidad de la clase trabajadora comunista y socialdemócrata, revolucionaria y reformista, y para responder a las necesidades obreras por alcanzar mejorías materiales ante los ataques de los empleadores, del fascismo y de una futura e inevitable guerra. Los historiadores citaban este proceder de Lenin como un ejemplo del pluralismo en su pensamiento y como el correctivo al pensamiento sectario que siguió tras la toma del poder en 1917 que propagaba la teoría de la ofensiva total al capitalismo Sin embargo, poco a poco el papel de Lenin y de la táctica del frente unido, como la flexibilización de las posturas iniciales del dirigente bolchevique, se empezaron a ver más bien como la continuación de su lucha ideológica contra el "social-reformismo" y como parte de la estrategia del Komintern por alcanzar la revolución mundial por otros medios. ${ }^{13}$

Aunado a lo anterior, los mismos historiadores rusos reconocieron que la posición de los bolcheviques en torno a la política del frente unido no era homogénea. Lenin, entre otros, creía en su viabilidad como el camino para atraer a los obreros al comunismo y consideraba la alianza con los dirigentes socialdemócratas como una necesidad. Otros dirigentes eran más pesimistas acerca de los resultados de una alianza de compromiso y concluyeron que si la táctica del frente unido no dio los frutos esperados fue porque los comunistas, como Lenin, sobrestimaron la

\footnotetext{
${ }^{13}$ McDermott, "Rethinking the Comintern", p. 38.
} 
inminencia del colapso de los partidos socialdemócratas y subestimaron la influencia de estos partidos entre los obreros europeos. Estos argumentos a favor y en contra de la táctica del frente unido como un proceso democratizador al interior de las filas comunistas contribuyeron a que la discusión se abriera a interpretaciones alternativas y la historia se volviera más compleja. La visión maniquea, la división entre héroes y villanos y la separación nítida entre la historia definida por la dirección leninista como opuesta radicalmente a la estalinista si bien no fue eliminada del todo quedó en entredicho.

En los años noventa los historiadores rusos llevaron la interpretación del Komintern más lejos aún y adoptaron la explicación del fracaso del frente unido como consecuencia de la subordinación del Komintern a los intereses de la seguridad del estado y como una táctica que fue diseñada para derrotar el reformismo y no para colaborar con él. Esta interpretación se parecía más a la posición monolítica que en las décadas anteriores habían propalado los estudiosos empapados en los paradigmas de la guerra fría. ${ }^{14}$ Sin embargo, la interpretación de los procesos históricos del comunismo nacional e internacional apenas empezaba.

Si bien la apertura de los archivos del Komintern era el primer paso necesario para entender mejor el devenir de los partidos comunistas, a su vez la historia de los partidos era una de las claves para comprender la historia del Komintern en su totalidad, pues los partidos eran considerados como las secciones nacionales de la Tercera Internacional. Este nuevo impulso dado al estudio de la Internacional Comunista atrajo en los años noventa a decenas de historiadores y científicos sociales rusos y extranjeros a Moscú para emprender el tanto tiempo postergado estudio de las trayectorias de los partidos comunistas nacionales, de los movimientos sociales que los partidos se propusieron dirigir y de las relaciones de aquellos partidos con los diversos aparatos del Komintern.

${ }^{14}$ Daniela Spenser, "Los archivos de la Internacional Comunista en Moscú”, en Memoria, núm. 74, enero-febrero de 1995, pp. 80-83.

\section{LA CRÍTICA DEL REVISIONISMO OCCIDENTAL}

Igual que los soviéticos, los estudiosos del comunismo en las universidades europeas y norteamericanas reorientaron en los años ochenta los enfoques sobre el Komintern y sus enlaces con el mundo exterior. En respuesta a la historiografía de la guerra fría por un lado, y de la ortodoxia comunista de los voceros partidistas por el otro lado, a finales de los años setenta surgió la corriente revisionista. Su característica principal era el esfuerzo por recuperar la historia de los hombres y las mujeres militantes que no figuraban en los anales de la historia oficial ni se mimetizaban con los aparatos de los partidos. Era una historia que trataba de desideologizar la narrativa y el análisis, de buscar la diversidad y la autonomía de formas de pensar, de actuar y de organizarse de la gente común, independientemente del partido. ${ }^{15}$

El revisionismo corregía, además, la miopía ideologizada de la historiografía que parecía estar al servicio del anticomunismo de la guerra fría. Esa corriente consideraba los partidos comunistas nada más que correas de transmisión de los "dictados" de Moscú y al comunismo como parte de una conspiración internacional de la URSS para ocultar su ambición por expandirse más allá de su esfera de influencia europea. Hecha la crítica, los revisionistas recuperaban la historia autóctona del comunismo nacional, regional y local, pero dejaban del lado la dimensión internacional de esta historia. Retrataban a los activistas en su vida cotidiana, organizados por el partido pero no siempre subordinados a él incondicional y ciegamente, recuperaban la multiplicidad y la polivalencia de las relaciones entre los obreros organizados y los sin organización, entre ellos y los dirigentes y con miembros de otros gremios y grupos sociales. Lograron, además, demostrar las condiciones históricamente dadas en

\footnotetext{
${ }^{15}$ Maurice Isserman, Which side were you on? The American Communist Party during the Second World War, Wesleyean University Press, Middletown, Connecticut, 1982; Roger Keeran, The Communist Party and the Auto Workers Unions, Bloomington, Indiana, 1980; a este género pertenece también James Scott, Weapons of the Weak: everyday forms of peasant resistance, Yale University Press, New Haven, 1985.
} 
diferentes países que permitieron que los partidos comunistas tendieran a atraer, o a repeler, a los movimientos sociales. Si bien los historiadores revisionistas lograron recuperar la historia olvidada o minimizada por los mismos comunistas, en el proceso de la revisión de las corrientes que criticaban dejaban de lado los enlaces de los comunistas con la URSS y con el ámbito internacional del Komintern. Uno de los argumentos para proceder así era porque las historias que privilegiaban las relaciones entre los partidos comunistas y la URSS solían ser deterministas y predecibles como si no hubieran existido otras opciones, mediatizadas por la diversidad y las experiencias individuales y colectivas y porque, a final de cuentas, las relaciones con la URSS subsumían la dimensión social a la política. ${ }^{16}$

La corriente revisionista recuperaba la diversidad social y cultural de la historia comunista, pero al excluir la dimensión internacional de la tradición comunista, subestimaba la identificación y la lealtad de los comunistas hacia la Unión Soviética. ${ }^{17}$ Así, la tarea que se le presentaba a la nueva historia del comunismo tenía que volver a hacer campesino y la cultura de la izquierda local, regional o nacional por un lado, y el ámbito internacional por el otro.

La reconexión entre la historia de los partidos comunistas nacionales y el Komintern y la Unión Soviética de los años veinte, treinta y cuarenta se facilitó con la apertura de los archivos. El acceso a las nuevas fuentes estimuló una franca explosión de trabajos sobre los vínculos y las articulaciones entre la Internacional Comunista y sus secciones nacionales. Los libros que inundaron las bibliotecas y las librerías en los años noventa fueron a menudo resultado de colaboraciones internacionales o colectivas.

${ }^{16}$ Eric Weitz, Popular communism: political strategies and social histories in the formation of the German, French, and Italian communist parties, 1919-1948, Ithaca, Nueva York, Western Occasional Papers, 32, 1992, p. 2.

${ }^{17}$ Geoff Eley, "International Communism in the Hey-Day of Stalin", en New Left Review, núm. 157, mayo-junio de 1986, pp. 90-100; Geoff Eley y Ronald Grigor Suny, "University of Michigan Project on International Communism", en International Labor and Working-Class History, 30, otoño de 1986, p. 103; Randi Storch, "Moscow's archives and the new history of the Communist Party of the United States", en Perspectives, vol. 38, núm. 7, octubre de 2000, pp, 44-50.

Los nuevos estudios lograron esclarecer viejas incógnitas como el origen y las circunstancias de importantes tomas de decisión, tanto en el ámbito nacional como en Moscú, que cambiaban el curso de la historia y las vidas de las personas. ${ }^{18}$

Pero así como surgieron estudios de alta calidad metodológica, aparecieron en el mercado libros que buscaban resaltar el lado oscuro de la historia comunista. En la primera fase de los nuevos escritos sobre el Komintern hubo quienes se dejaron llevar por lo sensacional de los documentos y los reproducían sin ningún enfoque critico hacia las fuentes. El Komintern fue descrito también como una banda de aventureros que después de 1917 había desviado la historia soviética de su curso normal. Esta interpretación se debía a que los mismos documentos se prestaron a la adopción del punto de vista policiaco, pues muchos de los expedientes abiertos a la consulta habían sido generados con la lógica inquisicional y en función de recoger información para monitorear la conducta y el pensamiento de los cuadros comunistas. Además, los expedientes reflejaban las circunstancias de absoluto secreto en las que habían sido compilados. ${ }^{19}$

$\mathrm{Al}$ lado de la lectura policiaca de los documentos, aparecieron estudios que encontraron en los nuevos acervos la confirmación de las viejas tesis de que de principio a fin la Unión Soviética y el Komintern mantenían a los partidos comunistas sometidos ideológica y organizativamente y los partidos servían los intereses

\footnotetext{
${ }^{18}$ Brigitte Studer, Un parti sous influence. La parti communiste suisse, une section du Comintern 1931-1939, L’Age d'Homme, Lausanne, 1994; Peter Huber, Stalins Schatten in die Schweitz. Schweitzer Kommunisten in Moskau, Chronos-Verlag, Zurich, 1994; Mikhail Narinsky y Jurgen Rojahn (eds.), Centre and Periphery: The History of the Comintern in the Light of New Documents, International Institute of Social History, Amsterdam, 1996; Kevin McDermott y Jeremy Agnew, The Comintern. A History of International Communism from Lenin to Stalin, St. Martin's Press, Nueva York, 1997; Pierre Broué, Histoire de l'Internationale Communiste, Fayard, París, 1997; Tim Rees y Andrew Thorpe (eds.), International Communism and the Communist International 1919-1943, Manchester University Press, Manchester, 1998; Tauno Saarela y Kimmo Rentola (eds.), Communism. National \& International, SHS, Helsinki, 1998; Antonio Elorza y Marta Bizcarrondo, Queridos camaradas. La Internacional Comunista y España, 1919-1939, Planeta, Barcelona, 1999. ${ }^{19}$ Brigitte Studer y Berthold Unfried, "At the beginning of a history: visions of the Comintern after the opening of the archives", en International Review of Social History, vol. 42, 1997, pp. 419-446.
} 


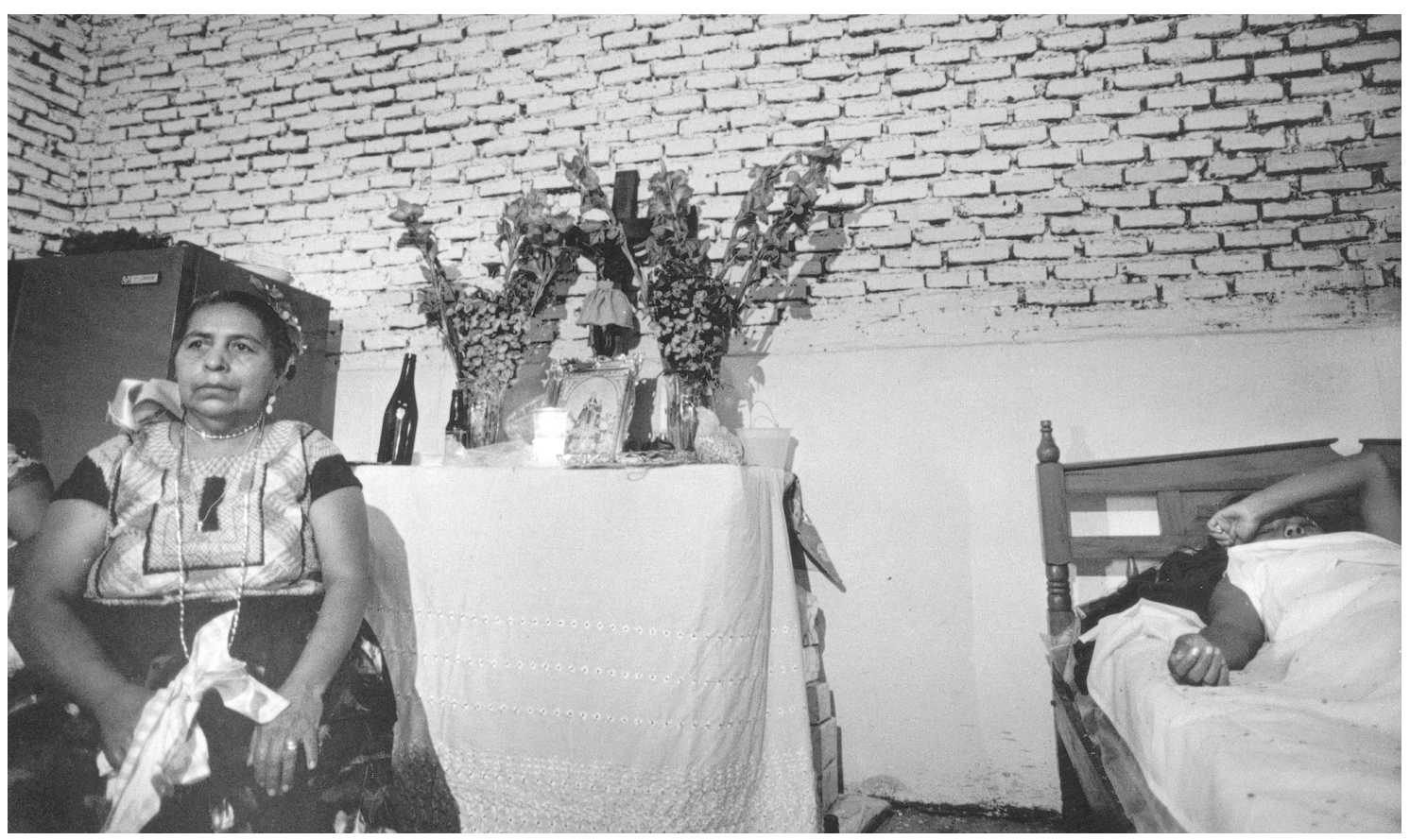

Juchitán, zapoteca del Istmo, Martha Toledo, 1998

soviéticos antes que los intereses nacionales. Esta corriente, desarrollada sobre todo en Estados Unidos, se ha distanciado del macartismo - la persecución política y judicial de comunistas y liberales en los años cincuenta mediante cargos excesivos, sin prueba y por asociación - para luego recurrir a los nuevos documentos como prueba de que el senador Joseph McCarthy exageró una realidad existente. Los mismos estudiosos del comunismo norteamericano retomaron la polémica con los revisionistas de los años setenta, que había terminado en un impasse gracias a la falta de documentos fidedignos. Ahora, con los documentos a la vista, estos estudiosos volvieron a los temas que trataron antes de la apertura de los archivos como por ejemplo los relativos al financiamiento del movimiento comunista en Estados Unidos por parte del Komintern y al espionaje de los comunistas norteamericanos a favor de la URSS. Como dijo uno de los expositores de esta corriente, el debate continúa. ${ }^{20}$

${ }^{20}$ John Earl Haynes, “The Cold War Debate Continues", en Journal of Cold War Studies, vol. 2, núm. 1, invierno de 2000, pp. 76-115; Harvey
Mientras que los historiadores de todo tipo y de varios países buscaban nuevos documentos en los archivos soviéticos con las más diversas herramientas conceptuales y metodológicas, un grupo de historiadores franceses publicó El libro negro del comunismo, en el que se propuso hacer una síntesis global del fenómeno como la historia del terror, análoga al totalitarismo de Hitler. El rescate de la memoria del terror era una obligación moral. ${ }^{21}$ Así como los historiadores que encontraron en los archivos la confirmación de las tesis elaboradas décadas antes de la apertura de los fondos documentales, los autores de $E l$ libro negro del comunismo — sin haber investigado en los archivos y sin haber esperado los frutos de los estudios de otros- volvieron a rescatar el enfoque totalitario de la historia, planteado después de la Segunda Guerra Mundial

Klehr, John Earl Haynes y Fridrij Firsov, The Secret World of American Communism, Yale University Press, New Haven, 1995, pp. 16-19; John Earl Haynes, Harvey Klehr y Kyrill Anderson, The Soviet World of American Communism, Yale University Press, New Haven, 1998.

${ }^{21}$ Stephane Courtois et al., El libro negro del comunismo. Crímenes, terror y represión, Planeta, Barcelona, 1998, p. 44. 
por Hannah Arendt y novelado por George Orwell. ${ }^{22} \mathrm{Se}-$ gún uno de los críticos de los autores y del polémico libro: "La base de su comprensión del comunismo era el argumento esencialista de que esta ideología tan sólo podría dar lugar a regímenes políticos represivos donde el poder se concentrara en una pirámide vertical con un líder en su vértice, cuya fuerza se sustentara en el recurso al terror." 23 Así, mientras que los archivos del Komintern permitían que la historia se volviera cada vez más compleja y matizada, los autores de El libro negro del comunismo ofrecieron una versión de condena moralista, una historia esquemática, basada en tipologías y clasificaciones del terror en lugar de "profundizar en la comprensión de las diversas causas del comunismo y su evolución en el siglo XX hasta su extinción" ${ }^{24}$ También del otro lado del derribado Muro de Berlín quedaba mucho trabajo por hacer.

\section{LOS TEMAS CENTRALES}

Entre 1919, año de su fundación, y 1943, cuando fue disuelta, la Internacional Comunista pasó por varios cambios ideológicos y etapas organizativas. Su significado ha sido debatido durante décadas, pero los historiadores no podían darle una explicación fundamentada mientras que los archivos del Komintern permanecían inaccesibles. Una vez abiertos, los acervos demostraron que los temas tradicionales seguían vigentes pero que hacía falta repensarlos a la luz de los nuevos documentos. Los temas relevantes de la historia del Komintern sobre los cuales había que volver a reflexionar eran, por ejemplo, el significado y la periodización de la idea de la revolución mundial que le daba la razón de ser a la Internacional Comunista, y los nexos y las articulaciones entre los partidos nacionales y la Internacional. Hacía falta un examen del seguimiento y la adopción de las líneas políticas que el Komintern formulaba y emitía, los partidos comunistas recibían y de

22 Hannah Arendt, Origins of totalitarianism, Penguin, Londres, 1958; George Orwell, Animal farm, Penguin, Londres, 1945.

${ }^{23}$ James Hughes, "Los intelectuales franceses y el terror comunista", en Revista de Libros, núm. 17, mayo de 1998, p. 4.

${ }^{24}$ Ibid., p. 7. múltiples maneras adaptaban a las condiciones de cada país. Sólo así se podían historizar y problematizar los llamados "dictados de Moscú".

Había que revisar el tráfico de las comunicaciones en la otra dirección, de los partidos a Moscú, así como los debates que las cartas e informes de los partidos suscitaban en los diferentes órganos del Komintern y del Partido Comunista de la URSS. Si bien el estudio de las comunicaciones en las dos direcciones y entre los ramales de la organización ayudaba a cuestionar al Komintern como un monolito, con los nuevos documentos los historiadores han podido distinguir entre el discurso y la acción de los partidos, de sus dirigentes y las organizaciones de base. El examen de los desencuentros entre los dirigentes

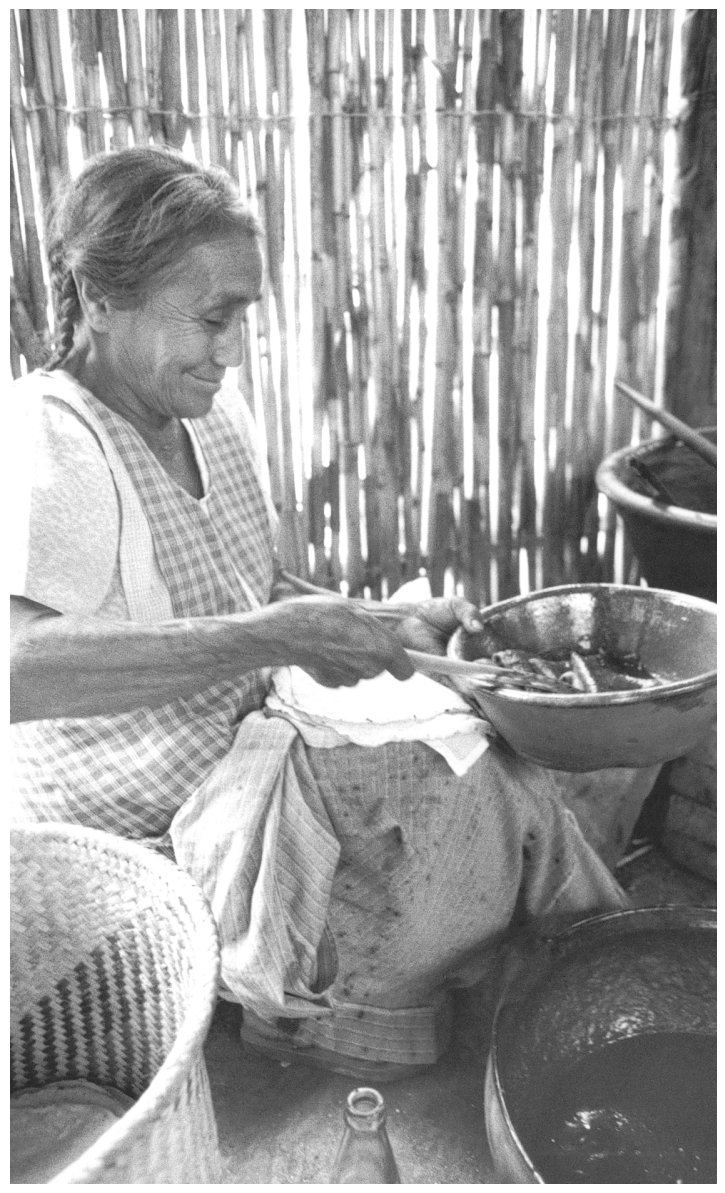

San Lorenzo Teitipac, zapoteca del Valle, Vittorio D’Onofri, 1995 
en Moscú y los de cada país ha permitido avanzar en el estudio de la cultura política nacional, regional y local y en desenterrar la historia social del comunismo. Comparados con la adopción de los "dictados de Moscú", como el sometimiento de los partidos y dirigentes a la política diseñada fuera de la región de su puesta en práctica, se ha podido estudiar el progresivo debilitamiento de la autoridad de las dirigencias nacionales frente a la Internacional. En el nexo entre los partidos nacionales, el Komintern y la política exterior de la URSS estaba la raíz del otro fenómeno de la historia comunista: la rusificación del Komintern y la bolchevización de los partidos. La dominación de la Internacional Comunista por el PCUS y la creciente interferencia de la organización internacional en la vida de los partidos ha permitido poner de manifiesto que a medida que el Komintern perdía su autonomía frente al Partido Comunista de la URSS, los partidos nacionales perdían su autonomía frente al Komintern.

Otros temas centrales de la historia del comunismo internacional revisados desde la apertura de los archivos han sido ligados a las personalidades del partido bolchevique: Lenin, Trotsky, Stalin, Nikolai Bujarin, Christian Rakovsky, Karl Radek y otros. ${ }^{25}$ La historia personal de los dirigentes bolcheviques marcó la historia de los partidos comunistas nacionales en la medida en que los dirigentes de los partidos se identificaban con uno u otro y con las corrientes políticas y de pensamiento que representaban. La lucha por el poder y por la definición del rumbo del partido que tenía lugar en la URSS, sobre todo en los años veinte, se trasladaba inevitablemente a los partidos nacionales aunque no necesariamente como su copia al carbón. Muchos de los personajes del comunismo soviético fueron exiliados, desaparecieron en los campos de trabajo forzado o durante los procesos fa-

${ }^{25}$ Neil Harding, Leninism, Duke University Press, Durham, 1996; Richard Pipes (ed.), The unknown Lenin, Yale University Press, New Haven, 1996; Robert Service, Lenin, 2000; Pierre Broué, Rakovsky, ou la revolution dans tous les pays, Fayard, París, 1996; Andrea Graziosi, "G. L. Piatakov (1890-1937): a mirror of Soviet history”, en Harvard Ukrainian Studies, vol. XVII, núms. 1-2, junio de 1992; Anna Larina, This I cannot forget. The memoirs of Nikolai Bukharin's widow, N.N. Norton, Nueva York, 1994; Amy Knight, Beria. Stalin's first lieutenant, Princeton University Press, Princeton, New Jersey, 1993. bricados en su contra en los años treinta. La persecución de los dirigentes bolcheviques en la URSS tuvo una réplica en los países cuyos partidos comunistas formaban parte del Komintern. Nuevamente, los documentos de los archivos soviéticos, y los estudios basados en ellos, nos permiten entender las formas en que estos procesos tuvieron lugar en el ámbito local y nos permiten describirlos con mayor detalle. ${ }^{26}$

Los cambios periódicos de las tácticas del Komintern han sido otro de los temas que la apertura de los archivos permitió estudiar a fondo. Se ha visto gracias al estudio en los acervos de los partidos comunistas nacionales en el archivo de la Internacional Comunista que no cada partido actuó de la misma forma ni que los cambios tuvieron el mismo efecto sobre todos los partidos al mismo tiempo. Por principio, el Komintern no reconocía las peculiaridades nacionales ni las raíces culturales de los pueblos y los cambios tácticos como la adopción de la alianza multiclasista contra el fascismo en los años treinta, llamada el frente popular, debía aplicarse por todos los partidos comunistas. Los estudios recientes proporcionan datos que evidencian que la colaboración entre los obreros comunistas y socialistas en un frente contra el fascismo data de 1933 cuando Hitler llegó al poder en Alemania, dos años antes de que el Komintern adoptara el frente popular como su táctica general. Entonces, los partidos comunistas como el checoslovaco y el francés adoptaron la política aun cuando la respuesta del Komintern fue tacharlos de oportunistas. ${ }^{27}$ Cuando finalmente fue adoptada, en Francia, por ejemplo, tuvo un enorme eco en las filas comunistas porque los socialistas y los comunistas habían llegado a la conclusión de tener que cerrar las filas junto con el Partido Radical para hacer

\footnotetext{
${ }^{26}$ Kevin Morgan, Harry Pollitt, Manchester University Press, Manchester, 1993; John Callaghan, Rajani Palme Dutt. A study of British Stalinism, Lawrence \& Wishart, Londres, 1993; Knight, Beria. Stalin's first lieutenant; Lars T. Lih, Oleg V. Naumov y Oleg V. Jlevniuk (eds.), Stalin's letters to Molotov, Yale University Press, New Haven, 1995. La identificación de dirigentes nacionales con los bolcheviques en desgracia como Trotsky ha tenido consecuencias funestas para la vida interna de muchos partidos comunistas, pues tildar a alguien con el epíteto de trotskista era suficiente en los años veinte para que cayera en ostracismo y en los años treinta para que fuera liquidado físicamente.

27 Wolikow, "Aux origines de la galaxie communiste", p. 210.
} 
frente al ascenso del fascismo en Europa. En cambio, su adopción tuvo que imponerse en países como México, en donde los comunistas no veían bondad alguna en unirse con un movimiento obrero organizado que consideraban la derivación de una Confederación Regional Obrera Mexicana corrupta y subordinada al Estado. ${ }^{28}$

Aunado a lo anterior, los nuevos estudios de la trayectoria del Komintern han permitido reemplazar la ahistórica noción de que de principio a fin era un brazo internacional del estado soviético o un monolito dominado por Lenin y luego por Stalin. Uno de los temas que iluminó este pasaje de la historia del Komintern era la reconstrucción de sus estructuras y del proceso interno de la toma de las decisiones. El estudio de los debates en el Komintern nos permite afirmar que, al menos en los años veinte, los asuntos que concernían a los partidos comunistas se discutían en un ambiente de diversidad de opiniones en los secretariados que eran organismos auxiliares del comité ejecutivo del Komintern encargados de los asuntos de cada región geográfico-política. De América Latina estaba encargado primero el secretariado latino y, a partir de 1926, el secretariado latinoamericano. $\mathrm{Al}$ abolirse los secretariados a mitad de los años treinta, según los estudiosos de los cambios en la estructura de la organización, terminó también la discusión hasta extinguirse cualquier intercambio de ideas; de allí en adelante los dirigentes nacionales eran responsables a un círculo estrecho de funcionarios del Komintern. ${ }^{29}$

Tradicionalmente también la historia del Komintern ha sido dividida en nítidos segmentos de tiempo que los

${ }^{28}$ Eric Weitz, Creating German Communism, 1890-1990. From popular protests to socialist state, Princeton University Press, Princeton, New Jersey, 1997; John Santore, "The Comintern's united front initiative of May 1934: French or Soviet inspiration", en Canadian Journal of History / Annales Canadieunes d'Histoire, vol. XVI, núm. 3, diciembre de 1981, pp. 405-421. Los documentos sobre México que se publicarán en el volumen 3 de la serie La Internacional Comunista en México en la p. 129 demostrarán el nexo entre el acercamiento de Vicente Lombardo Toledano al aparato del Partido Comunista de la Unión Soviética y su compromiso con la política del "frente popular mexicano" y con el presidente Cárdenas.

${ }^{29}$ Inessa Iazhborovskaia, "The Logic of the Development of the Organisational Structure and Mechanisms of Administration in the Comintern", en Narinsky y Rojahn, op. cit., pp. 57-73; Grant Adibekov y Eleonora Shajnazarova, "Reconstruction of the Komintern Organizational Structure”, ibid., pp. 65-73. historiadores transferían casi mecánicamente a la historia de los partidos, como si la totalidad fuera la suma de las partes. Los nuevos estudios han demostrado, sin embargo, que los cambios en las estructuras de la Internacional y las formas como se articulaba el Komintern con los partidos no necesariamente correspondía a los períodos comúnmente aceptados. Un ejemplo entre varios es el principio y el final de la táctica del frente unido. Oficialmente iniciada en 1921 y suspendida en 1928, en la práctica tenía una fuerza más allá de lo que podía lograr una directiva del respetado Komintern. En las tradiciones de las organizaciones obreras la solidaridad de los operarios en las fábricas tenía raíces profundas que las directivas del Komintern violentaban sin desarraigarlas del todo. ${ }^{30}$

Tampoco parecen precisos los años 1919 como el año fundacional del Komintern y 1943 como el año de su disolución. Varios estudiosos del tema han señalado que el internacionalismo y la búsqueda de la revolución mundial estaban en la agenda de los bolcheviques aun antes de que llegaran al poder. Lenin mismo propuso la idea de fundar la Tercera Internacional en 1914 después de que los socialdemócratas de la Segunda Internacional habían apoyado la agresión bélica de sus gobiernos nacionales. Por el otro lado, aunque 1919 es la fecha oficial de su fundación, no fue sino hasta 1920 cuando auténticas delegaciones extranjeras se reunieron en Rusia Soviética para participar en los debates del Komintern. En 1919 la mayoría de los participantes eran rusos, bolcheviques originarios de las regiones que habían formado parte del imperio ruso o extranjeros que habían sido prisioneros de guerra y se adhirieron al nuevo gobierno. Los que llegaron de los países occidentales porque evadieron el bloqueo de Rusia Soviética impuesto por las tropas invasoras, no representaban a organizaciones de masas. En cambio, el representante de la Liga Espartaca alemana, quien tuvo el mandato de su organización, se opuso a la fundación del Komintern por aquella razón.

Asimismo, aunque el año de 1943 se conoce como el de su disolución, el Komintern siguió funcionando y diri-

\footnotetext{
${ }^{30}$ Kevin Morgan, Harry Pollitt, Edward P. Johanningsmeier, Forging American communism: the life of William Z.Foster, Princeton University Press, Princeton, New Jersey, 1994.
} 
giendo las actividades de los partidos comunistas de manera encubierta de acuerdo con las necesidades de la política soviética del momento que incluía el apoyo brindado a los guerrilleros comunistas que en los países ocupados por Alemania combatían al nazismo y luego durante la guerra fría para que la URSS mantuviera apoyos en los países que le eran adversos. ${ }^{31}$

Otra fecha que entró en los anales del comunismo como definitoria es el año 1928. En el Sexto Congreso del Komintern se presentó a los delegados un panorama de la situación internacional radicalmente diferente de la que existía hasta entonces y la línea a seguir por los partidos comunistas tuvo que adaptarse a ella. De la estabilización del capitalismo y de la coexistencia entre la URSS y los países capitalistas, la situación mundial cambió, según el Komintern, a la crisis del régimen y la próxima confrontación entre los dos sistemas políticos. De allí se derivó la perspectiva de la inminencia de la revolución proletaria y los partidos comunistas tenían que prepararse para encabezarla.

Los estudios de esta coyuntura, basados en los nuevos documentos, demuestran una y otra vez que esta lectura de la historia hecha por el Komintern no coincidía con la experiencia ni de los partidos comunistas ni de los obreros, y que fue sujeta a arduos debates antes de que los partidos se sometieran a ella. El viraje a "la izquierda", que significó el repudio a la socialdemocracia en Europa y a los gobiernos de la pequeña burguesía en México, se llevó a cabo eventualmente, pero no antes de tener que cambiar las direcciones de los partidos y de hacer una limpieza de las oposiciones adentro de las organizaciones. ${ }^{32}$ Los cambios en las direcciones de los partidos obedecían a las dificultades de hacer adoptar líneas políticas que no

\footnotetext{
${ }^{31}$ Rojahn, "A matter of perspective: some remarks on the periodization of the history of the Communist International", en Narinsky y Rojahn, Centre and periphery, pp., 34-45.

32 Morgan, Harry Pollitt, op.cit.; Ted Morgan, A covert life: Jay Lovestone, communist, anti-communist and a spymaster, Random House, Nueva York, 1999. En México, el cambio de la dirección del partido en 1929 que encabezaba Rafael Carrillo por Hernán Laborde se originó en la resistencia del primero de abandonar la línea del frente unido y promover la fundación de la Confederación Sindical Unitaria de México (CSUM). Los documentos sobre el tema se presentarán en el volumen 3 de la serie La Internacional Comunista en México.
}

correspondían a los momentos históricos de las secciones nacionales. Para resolver estos desfases en las coyunturas claves, nuevas líneas requerían de nuevos hombres que el Komintern se encargaba de imponer.

\section{LAS MUTACIONES DE LA IDEA DE LA REVOLUCIÓN MUNDIAL}

Uno de los temas centrales en la historia y la historiografía del Komintern reelaborado después de la apertura de los archivos rusos es el significado de la idea y la cambiante

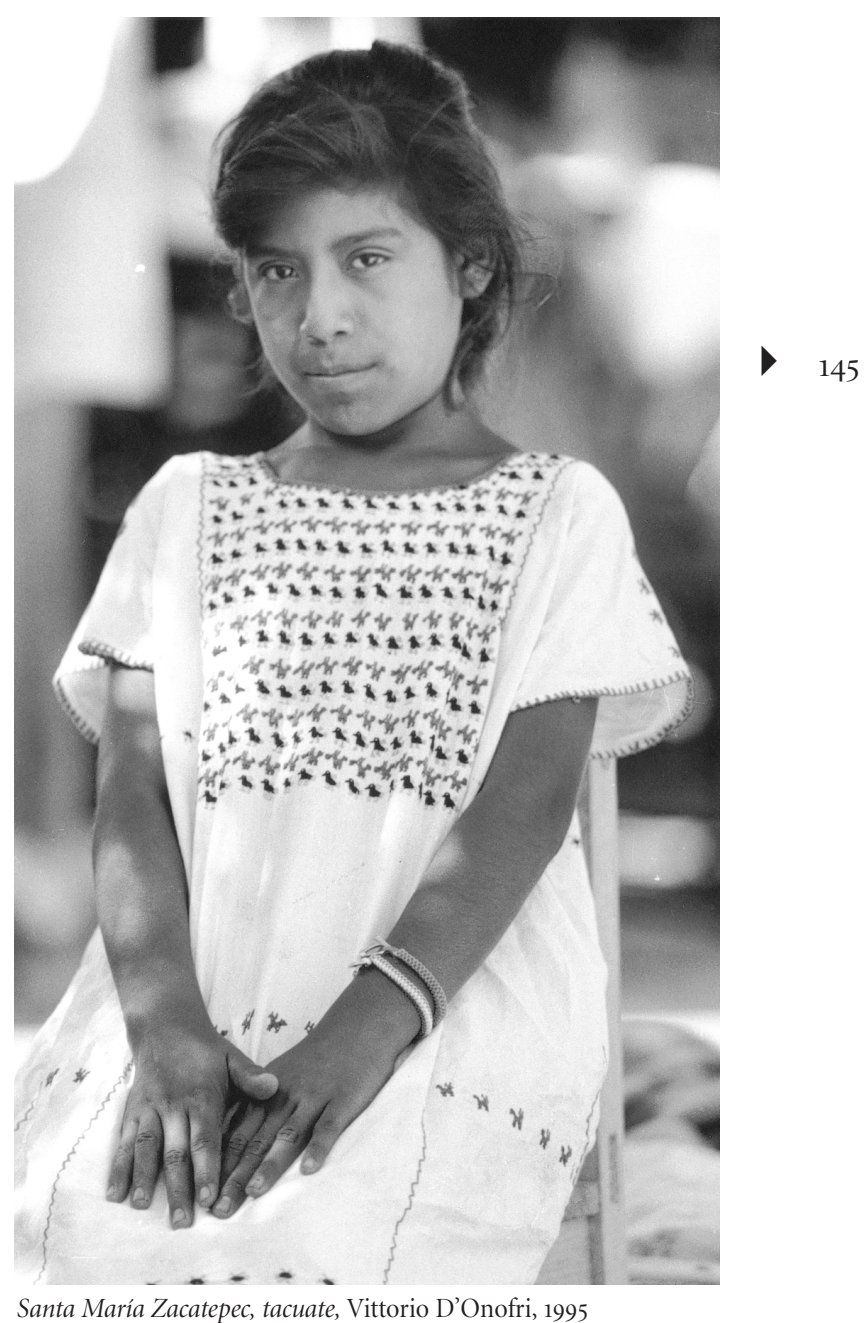


práctica de lo que era la misión del Komintern: promover la revolución mundial. Según la leyenda negra del comunismo, "[n]ada más acceder al poder, Lenin soñó con extender el ardor revolucionario primero a Europa y luego a todo el mundo" ${ }^{33}$ La reciente reflexión sobre la idea de la revolución mundial no ha cambiado la conclusión de que el propósito original de Lenin era unificar al proletariado de todo el mundo por todos los medios posibles para conquistar el poder detentado por las burguesías, y luego de Stalin de recurrir al movimiento comunista internacional para defender "el socialismo en un solo país". Sin embargo, en los años noventa los historiadores se vieron compelidos a volver a historizar y a refinar el análisis del proceso histórico ante la desaparición de los regímenes en Europa central, oriental y Rusia que fueron la derivación de la original revolución mundial.

Frente a la historiografía anticomunista, los historiadores nos han recordado que la idea de la revolución mundial pasó por una larga gestación empezando aun antes de la Revolución francesa y definida a partir de ella como la emancipación universal de los explotados y la supresión de la propiedad privada para alcanzar la distribución de los bienes de la naturaleza y del fruto del trabajo por medio de la insurrección armada. ${ }^{34}$ Lejos de ser la ocurrencia de un individuo, la idea de la revolución mundial era inherente al pensamiento radical decimonónico que los bolcheviques adoptaron como suya junto con el análisis clasista de Marx y Engels y la exhortación de "proletarios de todos los países, uníos" del Manifiesto comunista (1848). ${ }^{35}$

Los bolcheviques como Lenin y Trotsky consideraron el derrocamiento del Gobierno Provisional en octubre de

\footnotetext{
33 Stephane Courtois y Jean-Louis Panne, "La Komintern en acción", en Courtois et al., El libro negro del comunismo, op. cit., p. 309.

${ }^{34}$ La redefinición del comunismo no era el único legado de la Revolución francesa; el otro, no menos radical para la época, era el constitucionalismo y la institucionalización de la vía parlamentaria hacia la superación del régimen feudal. Véase Geoffrey Stern, The rise and decline of International Communism, Edward Elgar, Aldershot, Inglaterra, 1990, pp. 7-8.

35 Eric Hobsbawm, "La revolución mundial", Historia del siglo XX, cap. 2, Grijalbo Mondadori, Buenos Aires, 1998; Jakov Drabkin, "The idea of the world revolution and its transformations", en Narinsky y Rojahn, op. cit., pp. 46-54; Karl Marx y Friedrich Engels, Manifiesto comunista, Grijalbo, Barcelona, 1998, p. 84.
}

1917 como el primer triunfo de la larga trayectoria hacia aquella ineludible revolución. Sin embargo, no creían posible la consolidación de la Revolución bolchevique en Rusia mientras sus enemigos encontraban apoyo en las burguesías fuera del país. Además era evidente la precariedad de la Revolución de Octubre en sus primeros años debido al sitio en que la tuvieron los ejércitos occidentales y de Japón junto con los ejércitos blancos rusos, las distintas oposiciones al nuevo régimen entre los mismos comunistas y otras fracciones socialistas, y entre los campesinos y obreros no bolcheviques.

El estallido de la revolución en Europa era su esperanza. Visto desde la óptica de Rusia Soviética al fin de la Primera Guerra Mundial en 1918, el escenario europeo era semejante al ruso antes de la revolución y parecía ser un campo fértil para la irrupción de revoluciones similares a la bolchevique. Los imperios alemán, austrohúngaro y el otomano se desintegraron, y en Alemania y Hungría surgieron islotes revolucionarios que, sin embargo, fueron reprimidos por los herederos republicanos o monárquicos del poder imperial. No obstante esas derrotas, en 1919 la situación mundial parecía confirmar la convergencia entre la teoría y la práctica de la revolución mundial. Los bolcheviques interpretaron el descontento social y las economías en decaimiento en Europa, junto con su convicción que Rusia Soviética representaba el amanecer ideal de un futuro sin la explotación capitalista, sin la dominación de la burguesía, la instauración de la fraternidad y la emancipación universales, como el inicio de una nueva era. Si bien era evidente que los países europeos de la posguerra resintieron los efectos del conflicto bélico, los bolcheviques creyeron que el deseo de los pueblos de la paz iría de la mano con la revolución igual que había sucedido en Rusia.

Pero la revolución en los países europeos no estalló debido, en parte, al reordenamiento territorial y político según los principios de la autodeterminación de los pueblos propuestos por el presidente norteamericano Woodrow Wilson. Después de la desintegración de los imperios, las pequeñas naciones liberadas de la dominación imperial formaron sus estados con gobiernos constitucionales republicanos o monárquicos, mientras que los obreros alemanes radicales - la esperanza de los bolcheviques 
entre 1917 y 1919 — sufrieron derrotas dobles: por parte del gobierno socialdemócrata que los reprimió y por parte de sus pares que eran adversos a la política insurreccional. Así, después de la ofensiva revolucionaria inicial, la revolución mundial no se produjo, mientras que la rusa logró sobrevivir a pesar de los ataques para destruirla. ${ }^{36}$

La literatura reciente sobre el Komintern, dirigido todavía por Lenin antes de que cayera enfermo en 1922, ha adelantado la fecha del cambio de rumbo de la política mundial soviética. Basándose en los nuevos documentos, algunos historiadores aducen que el mismo Lenin perdió la confianza en la viabilidad de la revolución mundial después de que Rusia Soviética firmó el tratado de paz con Alemania en 1918, fue derrotada en su intento por conquistar Polonia para el régimen comunista en 1920, y cuando en 1921 introdujo la Nueva Política Económica mediante la cual reintrodujo las antes abolidas relaciones de mercado y la pequeña propiedad privada. ${ }^{37}$

A mediados de los años veinte, la idea y el contenido político de la revolución mundial cambiaron no sólo porque la revolución proletaria no se había producido en Europa capitalista (ni se produciría en China agraria) sino también gracias a la influencia de la percepción de un ala del partido bolchevique que la perspectiva para realizarse se alejaba a medida que las economías capitalistas se consolidaban en Europa y Estados Unidos. La nueva orientación dada a los partidos comunistas —adoptada por el Komintern en 1925 - era adaptarse a esta nueva e inesperada realidad. Con la nueva línea la Internacional estrechó la supervisión de la adopción de las nuevas tácticas para no perder la adhesión de los partidos, los sindicatos y los grupos simpatizantes con la Revolución bolchevique. ${ }^{38}$ "El socialismo en un solo país" expresaba

\footnotetext{
${ }^{36}$ Hobsbawm, Historia del siglo XX, p. 59-65.

37 Orlando Figes, A People's Tragedy. The Russian Revolution 1891-1924, Penguin, Nueva York, 1996, p. 550, 701, 769; Pipes (ed.), The unknown Lenin, p. 111.

38 Jakov Drabkin, "The idea of the world revolution and its transformation", en Narinsky y Rojahn, op. cit., pp. 46-54; Aldo Agosti, "World revolution and world party of the revolution: evolution of two concepts", trabajo presentado en la conferencia Historia del Comintern a la luz de los nuevos documentos, Moscú, 20-22 de octubre, 1994.
}

la confianza de Stalin de que la Revolución bolchevique podía existir independientemente de la revolución mundial en los países industriales. La revolución mundial no era insustituible.

La crisis económica mundial que estalló en 1929 confirmó y fortaleció la convicción de los bolcheviques que el sistema económico y político derivado de la Revolución de Octubre era superior al "decadente" capitalismo. El viraje que el Komintern implantó en su seno y extendió a los partidos comunistas fue el resultado de la interacción de la percepción de que la Unión Soviética sería atacada por las potencias capitalistas pero también de la lectura marxista de la historia que enseñaba que una crisis capitalista era la "partera de la revolución" mundial. En consecuencia, el viraje del Komintern significó no sólo la realización de una nueva línea, que requería de nuevos hombres para llevarla a cabo, sino la idea de que la revolución mundial era impensable sin la defensa de los intereses de la Unión Soviética, la "matria" del proletariado mundial. ${ }^{39}$ Una de las consecuencias del establecimiento de la nueva línea política, que condenaba a la socialdemocracia y a la pequeña burguesía como las expresiones del fascismo, fue la polarización de las ideologías y las organizaciones de trabajadores radicales y reformistas. ${ }^{40}$ Frente al ascenso del fascismo sin embargo, la idea de la revolución volvió a adaptarse a las nuevas circunstancias. Poco a poco la lucha por la revolución mundial se transfiguraba en la lucha contra el fascismo y el nacionalsocialismo. Aunque todavía en 1934 —un año después de que Adolf Hitler llegara al poder en Alemania desmantelando los sindicatos como uno de los primeros actos del régimen nacionalsocialista-Stalin declaró que en la conciencia de las masas alemanas maduraba la idea del asalto revolucionario al poder, ${ }^{41}$ en el VII Congreso del Komintern en 1935 la directiva a los partidos comunistas

\footnotetext{
${ }^{39}$ Drabkin, “The idea of the world revolution”, en Narinsky y Rojahn, op. cit., p. 52.

${ }^{40}$ Hay que insistir, sin embargo, en que las nuevas relaciones establecidas entre el Komintern y sus secciones no podían ser uniformemente impuestas debido a la diversidad de las situaciones y culturas nacionales. ${ }^{41}$ Richard Grunberger, A social history of the Third Reich, Penguin, Nueva York, 1968, p. 135; Drabkin, "The idea of the world revolution", p. 53 .
} 
volvió a cambiar de la lucha contra la socialdemocracia a la lucha contra el fascismo. A partir de entonces, la revolución mundial fue un objetivo relegado frente al nazifascismo y su discurso bélico, anticomunista, antidemocrático y antisemita.

El cambio radical de línea, de confrontación entre comunistas y reformistas a la colaboración en los frentes populares, era al mismo tiempo una admisión que la revolución mundial dejaba de ser una prioridad, o que era equivalente a la defensa de la Unión Soviética de sus enemigos. Esta política se complicó debido a los procesos fabricados en contra de los dirigentes del PCUS y la desaparición masiva de destacados cuadros del Komintern fue opacada por la Guerra Civil Española y la política exterior soviética que buscaba el statu quo en Europa. ${ }^{42}$ La expresión más fehaciente de que cualquier medio era válido fue exigirles a los partidos comunistas del Komintern que apoyaran el pacto de no-agresión entre Stalin y Hitler en 1939 para poner a la URSS a salvo de la próxima guerra, sin participarles que incluía el reparto de Polonia, la anexión a la URSS de los estados bálticos, de Bukovina y Besarrabia.

La idea de la revolución mundial perdió en realidad todo sentido durante la Segunda Guerra Mundial. Su partido, el Komintern, perdió la razón de ser. En 1943 la Tercera Internacional fue abolida sin la participación de los partidos comunistas nacionales en esa toma de decisión. De allí en adelante, la sección para la política exterior del PCUS se encargó de las relaciones con los partidos comunistas del mundo. ${ }^{43}$

\section{CONCLUSIONES}

Si bien el renovado interés de los estudiosos rusos en el Komintern fue una de las respuestas al intento de Mijail Gorbachov por reconstruir en la URSS el socialismo realmente existente, la investigación a fondo de la

${ }^{42}$ Kevin McDermott, "Stalinist terror in the Komintern: new perspectives", en Journal of Contemporary History, vol. 30, 1995, pp. 111-130; Wolikow, "Aux origines de la galaxie communiste", pp. 212-213.

43 Ibid., p. 216.
Tercera Internacional no empezó sino hasta después de que este proyecto demostrara su futilidad. Al abrirse los archivos del Komintern, el nuevo interés en el tema ha producido estudios originales en sus enfoques, métodos y problemas, al lado de trabajos que buscan arreglar las cuentas con el abigarrado pasado personal y colectivo de sus autores.

En 1996, los custodios de los archivos cerraron algunos de los acervos del Komintern. De acuerdo con el endurecimiento del gobierno ruso frente a los países occidentales, en Rusia se perdió el interés en revelar el atribulado pasado de la URSS. Aunado a lo anterior, las cabezas de las instituciones y los archivos se daban cuenta de la avidez de la academia, los medios y las empresas de información, occidentales sobre todo, por conocer los archivos y pagar por el acceso a la información. De esta manera, mientras que los archivos se cerraban al público en general, se llevaban a cabo (están llevándose a cabo) proyectos de colaboración internacional en beneficio académico y económico de las instituciones rusas que carecen de un adecuado financiamiento propio. Así, por ejemplo, a través del Consejo de Europa, el Consejo Internacional de Archivos y el Servicio Federal de Archivos Rusos se emprendió la digitalización de las guías a los acervos del archivo del Komintern. La empresa en informática Gale Group de Michigan, Estados Unidos, así como Chadwyck-Heeley de Gran Bretaña, han microfilmado extensamente en el archivo del Comité Central del PCUs que está cerrado casi en su totalidad al público. La Biblioteca del Congreso en Washington ha logrado microfilmar la gran parte del archivo del Partido Comunista de Estados Unidos. De esta manera y a pesar de que algunos archivos en Moscú dejaron de ser accesibles, en las bibliotecas existen ya miles de documentos disponibles para su estudio.

El comunismo ha sido, sin duda alguna, uno de los fenómenos más importantes del siglo XX. Es alentador poder constatar que, dada la complejidad del fenómeno, su estudio apenas ha empezado y no se podrá conocer en toda su extensión y profundidad hasta que no conozcamos el conjunto de las relaciones entre la organización que quería ser mundial y totalizadora, y las experiencias nacionales, regionales y locales que redefinían aquel proyecto unificador. 